\title{
Hematuria Associated With Sickle Cell Trait During Pregnancy
}

\author{
Andrea Videlefsky, MD, and Wayne Blount, MD, MPH
}

Although sickle cell trait is usually considered a benign condition, it has frequently been associated with hematuria and an increased incidence of pyelonephritis. This case report highlights the complications that can occur with sickle cell trait in a pregnant patient. Pregnancy enhances the susceptibility for renal problems, and pregnant patients who develop complications require close monitoring for anemia, which can ultimately cause renal or uteroplacental insufficiency and pose a threat to the fetus. We would like to alert physicians doing routine antenatal care to serious complications that can arise in patients with a sickle cell trait.

\section{Case Report}

A 30-year old woman (gravida 4, preterm 0 , term 2 , abortion 1 , alive 2 ) attended the family medicine clinic for routine antenatal care at 6 weeks' gestation. She had no history of any serious medical illnesses, she did have sickle cell trait (HbAS), and she denied a history of alcohol, tobacco, or drug abuse.

Her family history was notable for a first-born child with sickle cell trait, a second-born child with sickle cell disease (sickle cell, $\alpha$-thalassemia), and an elective abortion. With regard to the current pregnancy, the father, who was a different sexual partner from the father of the previous pregnancies, was sickle cell negative. This patient had not had any previous episodes of hematuria. Her mother did not experience any problems in her pregnancies, but two paternal aunts had episodes of gross hematuria unrelated to pregnancy.

The patient had an uneventful pregnancy until 17 weeks' gestation, when she sought care for an episode of nausea and vomiting. There was no associated abdominal pain, but she did have ketones

Submitted, revised, 17 November 1997.

From the Department of Family and Preventive Medicine, Emory University School of Medicine, Atlanta. Address reprint requests to Andrea Videlefsky, MD, Suite $818 \mathrm{~A}$ Candler Building, 478 Peachtree St. NE, Atlanta, GA 30308. in her urine and was advised to remain well hydrated. Two weeks later she had ongoing nausea and evidence of microscopic hematuria. Urine was sent for culture, and trimethoprim-sulfamethoxazole was prescribed as empiric oral antibiotic therapy. Urine culture proved negative.

One week later she developed gross, painless hematuria, and a thorough work-up was initiated: The patient denied a history of abdominal trauma. Premature labor was excluded, a microscopic examination was negative, and a repeated urine culture remained negative. A renal sonogram showed a focal echogenic $2.9 \times 2.1-\mathrm{cm}$ defect in the dependent portion of the bladder with no evidence of obstructive uropathy. No intrarenal masses or calculi were seen. Cystoscopic examination showed a clot in the dependent portion of the bladder and bleeding from the left ureter. Conservative therapy, including alkalinization of the urine, increased fluid intake, and bed rest, was instituted, but the hematuria persisted.

Four weeks after the initial patient encounter, the patient was admitted for a trial of intravenous antibiotic therapy and a blood transfusion because her hemoglobin had dropped from $11.8 \mathrm{~g} / \mathrm{dL}$ to $8.2 \mathrm{~g} / \mathrm{dL}$. Monitoring throughout this 7 -day period indicated no ill effect to the fetus. Screening for bleeding abnormalities and clotting factor deficiencies, including Von Willebrand disease, disclosed no abnormalities as evidenced by a normal bleeding time, platelets, prothrombin-partial thromboplastin time, and coagulation factor VIII levels. The white cell and differential counts were normal. Cytologic examination of the urine showed benign transitional cells and evidence of acute inflammation. A left intraureteral stent was placed to prevent obstruction secondary to clots or inflammation.

Despite conservative therapy the hematuria persisted. Two weeks later the intraureteral stent was removed because of persistent lower abdominal pain and cramping. Close fetal monitoring showed evidence of fetal distress during an epi- 
sode of relative dehydration. Bed rest and active rehydration resulted in abatement of hematuria and resolution of fetal distress. At 30 weeks' gestation the patient required an additional blood transfusion and was transferred to a maternal and fetal medicine clinic for high-risk obstetric care. She remained asymptomatic with no further evidence of hematuria. At 40 weeks' gestation labor was induced, and she gave birth to a healthy male infant without any complications. A postpartum intravenous pyelogram showed evidence of papillary necrosis, an associated renal abnormality in patients with sickle cell trait.

\section{Discussion}

Renal abnormalities associated with sickle cell disorders have been reviewed. ${ }^{1}$ A number of studies assessing the outcome of pregnancy in patients with sickle cell trait indicate that the most common antenatal complications of sickle cell trait include recurrent urinary tract infections and hematuria in the mother (incidence 6.0 percent and 16.5 percent, respectively)..$^{2-4}$

Other serious complications noted by several authors include fetal distress during labor (17 percent), an increased incidence of delivery by emergency cesarean section ( 11.5 percent), ${ }^{3}$ postpartum pulmonary embolism, ${ }^{5}$ and a case report of maternal death while under general anesthesia during cesarean section. This death was thought to be related to concealed aortocaval compression with subsequent release of large-volume, acidotic, hypoxemic blood with sickled cells. ${ }^{6}$

A review of a community hospital obstetric experience noted an increased incidence of pyelonephritis, refractory anemia, and premature rupture of membranes and prematurity. These authors recommend classification of patients with sickle cell trait as high-risk obstetric patients. ${ }^{7}$

Fetal birth weight as a predictor of pregnancy outcome has been controversial. Some authors have claimed a statistically significant decrease in mean birth weight in babies born to women with sickle cell trait when compared with a matched population of normal patients, ${ }^{8}$ while others have claimed no difference in outcome for birth weight in pregnancy. 9,10

Many persons with sickle cell trait cannot form concentrated urine when deprived of water because of a disturbance of the countercurrent exchange mechanism. ${ }^{11}$ The mechanism of hema- turia in sickle cell trait is related to the relative hy: pertonicity, hypoxia, and acidosis in the vasa recta of the renal medullary area, hence increasing the propensity of red blood cells to sickle. Pregnancy predisposes to dehydration and thus results in an enhancement of these mechanisms. The increased sickling tendency leads to capillary blockade, which ultimately causes congestion, stasis, and ischemia with resultant perivascular exudation and hemorrhage. These areas serve as a nidus for bacterial lodgment and growth and could be the cause for the well-known increased incidence of pyelonephritis during pregnancy and the puerperium in women with sickle cell trait. ${ }^{12}$

The left kidney has been noted to be the more common site of bleeding, six times more frequently than the right kidney. ${ }^{13}$ This predisposition could be related to the anatomy of venous drainage, as the vein from the upper pole of the left kidney passes under the renal artery before joining the left renal vein. The increased mechanical pressure on the vein predisposes to stasis of blood. Bleeding from the left kidney has also been found to be less responsive to conservative therapy.

For patients with hematuria in pregnancy, emphasis should be placed on establishing an accurate diagnosis. The differential diagnoses include infection, calculi, bleeding disorders, renal neoplasms, renal arteriovenous malformations, trauma, sickle cell disease, or, by exclusion, sickle cell trait. For patients who have hematuria secondary to sickle cell trait, the fetus should be closely monitored, and conservative measures to stop the bleeding should be instituted. In most patients the hematuria resolves with conservative measures. Supportive care, including blood transfusions for patients who develop severe anemia, might be required.

Sickle cell trait, especially in pregnant patients, is not a completely benign condition. Hematuria can lead to severe anemia and renal compromise in the mother and subsequent uteroplacental insufficiency with fetal compromise. Further studies are required to establish the prevalence and morbidity associated with this disorder.

\section{References}

1. Schlitt LE, Keitel HG. Renal manifestations of sickle cell disease: a review. Am J Med Sci 1960; June:773-8.

2. Lucas WL, Bullock WH. Hematuria in sickle cell disease. J Urol 1960;83:773-41. 
3. Tuck SM, Studd JW, White JM. Pregnancy in women with sickle cell trait. $\mathrm{Br} \mathrm{J}$ Obstet Gynaecol 1983;90:108-11.

4. Baill IC, Witter FR. Sickle trait and its association with birthweight and urinary tract infections in pregnancy. Int J Gynaecol Obstet 1990;33(1):19-21.

5. Van Dinh T, Boor PJ, Garza JR. Massive pulmonary embolism following delivery of a patient with sickle cell trait. Am J Obstet Gynecol 1982;143:722-4.

6. Intraoperative death during caesarian section in a patient with sickle cell trait. Anaesthesia Advisory Committee to the Chief Coroner of Ontario. Can J Anaesth 1987;34(1):67-70

7. Rimer BA. Sickle cell trait and pregnancy: a review of a community hospital experience. Am J Obstet Gynecol 1975;123(1):6-11.
8. Roopnarinesingh S, Ramsewak S. Decreased birth weight and femur length in fetuses of patients with the sickle cell trait. Obstet Gynecol 1986;68(1):46-8.

9. Blattner P, Dar II, Nitowsky IIM. Pregnancy outcome in women with sickle cell trait. JAMA 1977; 238:1392-4.

10. Okonofua FE, Odutayo R, Onwudiegwu U. Maternal sickle cell trait is not a cause of low birthweight in Nigerian neonates. Int J Gynaecol Obstet 1990; 32:331-3.

11. Berman LB. Sickle cell nephropathy. JAMA 1974; 228:1279.

12. Whalley PJ, Pritchard JA, Richards JR. Sickle cell trait and pregnancy. JAMA 1963;186,:1132-5.

13. Platt HS. Effect of maternal sickle-cell trait on perinatal mortality. Br Med J 1971;4:334-6. 